Developing predictive models for polycyanurates through a comparative study of molecular simulation and empirical thermo-mechanical data

Ian Hamerton, Brendan J. Howlin*, Paul Klewpatinond, Foluke Osubu, and Hannah J. Shortley

Chemistry Division, School of Biomedical and Molecular Sciences, University of Surrey, Guildford, Surrey, GU2 7XH, U.K.

\title{
Shinji Takeda
}

Laboratory for Advanced Materials, Research and Development Centre, Hitachi Chemical Co., Ltd., 4-13-1 Higashi, Hitachi, Ibaraki 317-8555, Japan.

* correspondence should be addressed to Dr Brendan J. Howlin, Chemistry Division, School of Biomedical and Molecular Sciences, University of Surrey, Guildford, Surrey, GU2 7XH, U.K., telephone number +44 (0) 1483 686834, facsimile +44 (0) 1483686851 , b.howlin@surrey.ac.uk

Other papers in this series:

Hamerton, I.; Howlin, B. J.; Klewpatinond, P.; Takeda, S. Polymer, 2002, 43, 4599.

Hamerton, I.; Howlin, B. J.; Klewpatinond, P.; Takeda, S. Polymer, 2002, 43, 5737.

Hamerton, I.; Emsley, A. M.; Howlin, B. J.; Klewpatinond, P.; Takeda, S. Polymer 2003, 44,4839

Hamerton, I.; Emsley, A. M.; Howlin, B. J.; Klewpatinond, P.; Takeda, S. Polymer, 2004, 45, 2193 
ABSTRACT: Using a parameter set (RDA-DR2.21_Inv) previously published by our group, both the atom-to-atom connectivities and geometries and the physical and mechanical properties of poly[bis-4-(4-cyanatophenoxy)phenyl sulphone] have been simulated with remarkable accuracy. Molecular dynamics simulation, carried out on the polymer structure at a variety of experimental temperatures, yields a transition temperature of $c a$. 510-520 K, which can be equated with the empirical glass transition temperature $\left(\mathrm{T}_{\mathrm{g}}\right)$ for the polycyanurate. The same dicyanate was prepared experimentally and characterized using dynamic mechanical analysis (yielding an empirical $\mathrm{T}_{\mathrm{g}}$ of $c a .246 \mathrm{~K}$ ) and thermo-mechanical analysis (yielding an empirical $\mathrm{T}_{\mathrm{g}}$ of 508-528 K). The effect of incomplete cure of the monomer or development of structural defects in the network on the thermo-mechanical properties is also examined using molecular simulation.

\section{Introduction}

Cyanate ester resins (polycyanurates) are a family of thermosetting resins that are used within a variety of electronic and microelectronic applications. Once cured, polycyanurates offer high performance, including relatively high glass transition temperature $\left(\mathrm{T}_{\mathrm{g}}=463-563 \mathrm{~K}\right.$, depending on structure and degree of cure), high fracture toughness (typically $\mathrm{G}_{\mathrm{IC}}=140-225 \mathrm{~J} \mathrm{~m}^{-2}$, although this can be raised significantly by blending with engineering thermoplastics) and good hot/wet performance $^{1}$. Currently, the single largest application for polycyanurates is as lamination substrates for printed circuits and their assembly via prepreg adhesives into high-density, high-speed multi-layer boards, which are produced commercially for supercomputers, mainframes and high speed workstation mother units ${ }^{2}$. Polycyanurates also develop interesting dielectric properties (typically, the dielectric constant is 2.2-2.7 and the dissipation factor is 0.003 at $\mathrm{GHz}$ frequencies) that make them particularly attractive in these applications, for which epoxy resins and polyimides are market contenders.

Polyfunctional cyanate monomers cure via the formation of cyanurate rings (sym-triazine rings linked by aryl ether linkages to a polymer, correctly termed a polycyanurate) and a simplified reaction is depicted in Scheme 1 for bis-4-(4cyanatophenoxy)phenyl sulphone (catalyst packages typically comprise a transition metal carboxylate or chelate and an alkyl phenol).

\section{Insert Scheme 1}

Simplified cyclotrimerisation reaction to produce polycyanurate network (shown for bis-4-(4-cyanatophenoxy)phenyl sulphone). 
Although this reaction scheme predominates during the polymerization, it is now recognised that the earlier claims for the exclusive formation of cyanurate rings ${ }^{3}$ were somewhat optimistic and there is still debate about the exact nature of the polymerization mechanism. Many routes have been proposed to acknowledge the effects of different catalysts and reaction intermediates - a fuller discussion of this aspect is outside the scope of the current paper although the reader is directed to other sources $^{4,5,6,7,8}$ in which this is dealt with in some detail.

For almost fifteen years, research at Surrey has examined, with some success, how synthesis might yield polycyanurates (and indeed many other engineering polymers) with superior properties to existing polymers, or how chemical modification might be employed to increase the utility of commercial dicyanates. During this time, many monomers, blends and copolymers have been prepared (on a variety of scales) through the efforts of a team of researchers, characterised and tested for their physical and mechanical properties. This effort has, of necessity, involved many chemicals, much analysis time and the involvement of many laboratory hours "at the bench". In common with "traditional" chemical synthesis involving the preparation of "small" organic molecules, polymer synthesis brings many similar challenges and a few additional problems (e.g. limited solubility or reduced reactivity) arising from the extended chain structure. However, no matter what the nature of the preparation (whether fine chemicals, pharmaceuticals, agrochemicals or polymers), every synthesis will require that reaction conditions (e.g. temperature, solvent, pressure, reagents, and catalysts, etc.) are optimised. Furthermore, every preparation will consume energy and feedstock materials and generate waste (in the form of gaseous emissions, solvated (by)products or solid matter - the latter may be the desired product, but might also be accompanied by contaminants. It is self evident 
that energy requirements should be recognised for their environmental and economic impacts and to reduce them accordingly and that the prevention of waste is preferable to the treatment or clean-up of waste after it has formed.

Anastas and Warner have discussed, at length, the role that chemistry has in reducing the and as a result have formulated their "twelve principles of green chemistry" 9 . Recently, a thirteenth principle was mooted ${ }^{10}$ namely that "where possible, the reliable simulation or prediction of materials properties should be employed to optimise synthesis and reduce its impact on the environment". The increasing advances made in computational power make the use of simulation techniques increasingly useful in the rational design of new materials. By adopting much of the methodology piloted with great success by the pharmaceutical industry to model the interaction of drug molecules with the active sites of proteins ${ }^{11}$, molecular modelling has become generally accepted as a powerful technique for understanding some of the properties exhibited by materials. While still in its infancy in the field of polymer chemistry, computational chemistry has the potential to simulate the properties of novel materials, as yet unsynthesised. There is also the possibility of employing molecular simulation in a predictive capacity potentially offering savings in both labour and cost and reductions in chemical waste. Ultimately, this would allow the scientist or engineer to examine the potential of a novel structure to give him or her the required properties (e.g. heat resistance, bulk modulus or glass transition temperature) to fulfil a new application, without having to prepare the actual material in the laboratory. For although computation experiments do consume energy, the additional burdens, which synthesis places on the environment, would be largely avoided or dramatically reduced. At a later stage, the new monomer or polymer would be prepared in order to allow small scale testing, prior to scale up, but 
extensive exploratory syntheses to develop many potential monomers would be unnecessary.

A laudable aim, but how realistic is this aspiration? In 1996 Boyd published $^{12}$ a useful review detailing the state of the art (at that time) for the simulation of the glass transition from molecular dynamics simulations. He concentrated on engineering thermoplastics, but the simulation of linear and branched thermoplastics is conceptually simpler to achieve (than e.g. thermosetting polymers) and can yield good correlation with empirical data ${ }^{13,14}$. The simulation of network-forming polymers is necessarily somewhat more difficult in view of the structural complexity and the need to produce a representative model structure. Having published an early study to examine the thermo-mechanical properties of a polycyanurate ${ }^{15}$ involving a rather crude model, albeit advanced for its time, we now present a more sophisticated model. In this paper we examine the effect of network defects on the behaviour of a well-characterised polycyanurate. The results of the simulations will be compared to empirical thermal and mechanical data.

\section{Experimental Section}

Materials. The details of the preparation and characterization of bis-4-(4cyanatophenoxy)phenyl sulphone (see monomer structure in Scheme 1) are reported elsewhere $^{16}$. It is worth noting that the combination of analytical techniques confirmed that the monomer had been produced in good yield and high purity (a purity of $98.4 \%$ was recorded by $\mathrm{HPLC}^{8}$ ).

Procedure for blending of the dicyanate and co-catalysts and cure schedule employed to effect cure. Prior to incorporation in the dicyanate, the co- 
catalyst package, comprising aluminum(III) acetylacetonate and dodecylphenol in the molar ratio of $1: 25$, was first homogenised by heating to $353 \mathrm{~K}$ (in a vial in a water bath) before cooling to room temperature. The co-catalysts were then introduced into the dicyanate monomer (typically at a molar ratio of aluminum(III) acetylacetonate:dodecylphenol:monomer of 1:25:1000) by mixing in a pestle and mortar at room temperature to a homogeneous mixture. The ensuing formulations were used in the thermal analyses directly after incorporation of the co-catalysts. Storage of catalyzed formulations was undertaken in a refrigerator $(<278 \mathrm{~K})$ with care being taken to minimise the exposure of the sample to atmospheric moisture. Prior to the dynamic mechanical analysis (DMA) and thermomechanical analysis (TMA) measurements, the catalysed monomer was cured thermally by application of the following cure schedule: $423 \mathrm{~K}$ (1 hour), $453 \mathrm{~K}$ (5 hours) and $503 \mathrm{~K}$ (5 hours).

Apparatus. Fourier transform infrared (FT-IR) spectra were recorded using a Perkin-Elmer (system 2000 FT-IR) spectrometer interfaced with a PC running PEspectrum v 2.00 software. The samples were presented on an ATR module, 16 scans, at a resolution of $4 \mathrm{~cm}^{-1}$, were recorded and co-added to produce the final spectrum. Dynamic mechanical analysis measurements were undertaken in tensile mode at a frequency of $1 \mathrm{~Hz}\left(6.28 \mathrm{rad} \mathrm{s}^{-1}\right)$, on cured neat resin samples of $5 \times 0.5 \times 35 \mathrm{~mm}^{3}$ using a Rheometrics solids analyzer RSA II with a Rheometrics environmental controller unit. Scanning experiments were performed between $123 \mathrm{~K}$ and $623 \mathrm{~K}$ at a heating rate of $5 \mathrm{~K} \mathrm{~min}^{-1}$. Thermomechanical measurements were undertaken using a Seiko Instruments, Inc. EXSTAR6000 TMA/SS6000 on cured neat resin samples of between 0.7 and $1.1 \mathrm{~mm}$ thickness. A probe weight of $0.5 \mathrm{~g}(4.9 \mathrm{mN})$ was used on an analysis area of $9.026 \mathrm{~mm}^{2}$, while being scanned at a heating rate of $5 \mathrm{~K} \mathrm{~min}^{-1}$. The 
density the cured polymer sample was measured using Archimedes' principle (by measuring displacement of fluid from an immersion tank) at $298 \mathrm{~K}$ using a Mirage Trading Co., Ltd. SD200L electronic densimeter.

Modelling Methodology. Molecular simulations of the polycyanurate were performed using a Silicon Graphics Origin 2000 multiprocessor machine termed 'Proton' at the U.K. Computational Chemistry Facility at The Rutherford Appleton Laboratory. The calculations ran under Irix 6.3 with the Cerius ${ }^{2}$ (Accelerys, Inc.) software package. Energy minimisations were achieved using a modified Dreiding v.2.21 force field (RDA-DR2.21_Inv), previously reported for similar polycyanurate structures $^{17}$, in conjunction with the Qeq charge calculation ${ }^{18}$.

Molecular mechanics (MM) study. The dicyanate monomer, bis-4-(4cyanatophenoxy)phenyl sulphone is shown in scheme 1. Initially, a two-dimensional model was constructed (using the three-dimensional, 3-d, builder module) on an atom-to-atom basis to form a sym triazine ring with explicit hydrogen atoms and with each $O$-substituent left as a non-bonded cyanate group (i.e. to form the molecule tris(4-cyanatophenoxy-1,3,5-triazine)). Energy minimisation was performed on this molecule using the conjugate gradients routine achieved convergence to an RMS force of $0.01 \mathrm{kcal} \mathrm{mol}^{-1}$. Three more triazine rings were added, each with two bonded carbon atoms in the triazine ring and one free carbon atom, allowing the three pairs to be bonded when the 3-d structure was built. This structure was minimised until convergence, again to an RMS force of $0.01 \mathrm{kcal} \mathrm{mol}^{-1}$. In order to apply periodic boundary conditions (PBC), two cells were visualised in the $x$-axis by moving necessary bonds close to one another and removing cell boundaries. The 3-d lattice 
(Figure 1) was then built up by connecting the three pairs on non-bonded cyanate groups and non-bonded carbon atoms in the triazine rings, across the $x, y$ and $z$ directions of the structure. This was the starting point for the energy minimisation in the MM studies.

\section{Insert Figure 1}

"unit cell" of bis-4-(4-cyanatophenoxy)phenyl sulphone (N.B., oxygen atoms are shown in red, nitrogen atoms in blue, sulphur atoms in yellow, carbon atoms in black and hydrogen atoms in white)

Periodic cells were constructed and three cycles of 10 ps molecular dynamics and 100,000 steps of energy minimisation were then performed to reach an optimum density for the monomer. Density, volume and cell dimensions, were calculated for the molecule (Table 1) and the bond distances and angles presented in Table 2 for the dicyanate monomer.

\section{Insert Table 1}

Summary of data derived from Cerius ${ }^{2}$ experiments for bis-4-(4cyanatophenoxy)phenyl sulphone) (for a given structural conformation)

\section{Insert Table 2}

Bond distances and angles of the sym triazine ring for bis-4-(4cyanatophenoxy)phenyl sulphone obtained using the RDA-DR2.21_Inv forcefield (for the given conformation) 
Molecular dynamics (MD) study. The MD module in Cerius ${ }^{2}$ was used to simulate the glass transition temperature $\left(\mathrm{T}_{\mathrm{g}}\right)$ by monitoring changes in cell volume, while keeping the number of atoms present, pressure and total energy constant. The volume change at a specified temperature was recorded after a period of $250 \mathrm{ps}$ simulation steps. Simulations were initially conducted at $700 \mathrm{~K}$ and thereafter at 100 $\mathrm{K}$ intervals to a minimum of $200 \mathrm{~K}$ and changes in cell volume were plotted against the entire working range of temperature.

\section{Results and Discussion}

During the last decade, several groups have reported results from conformational studies of the sym triazine ring structure (and many fragments containing sym triazine rings) by means of computer modelling. There have also been some previous studies by our group involving molecular modelling of polycyanurates ${ }^{15,19}$ as well as some studies of network build up in the same polymers conducted by other researchers ${ }^{20,21}$. However, this paper represents a new and exciting step in this process. Our work has been advancing towards the reliable prediction of physical and mechanical properties in polymers from molecular simulation. In this way the decision might be made whether the synthesis of a novel monomer (or untested polymer) might be worthwhile to achieve a particular set of performance characteristics. To this end, in a previous paper ${ }^{16}$ we reported a molecular simulation study of three commercially available polycyanurates. The materials, 2,2-bis(4-cyanatophenyl)propane (available commercially as AroCy B-10), 1,1-bis(4-cyanatophenyl)ethane (AroCy L-10) and 1,3-bis(4-cyanatophenyl-1-(1methylethylidene))benzene (XU 366), were selected on the basis that they were well known and their physical and mechanical characteristics had been well documented in 
the literature. These were selected in order to validate the parameter set that we have employed in this work. Naturally, it should be borne in mind that a study of this kind cannot indicate whether a proposed molecule can be synthesised, only whether it would have desirable properties if it could be synthesised.

Molecular mechanics data. The unit cell data (derived from Cerius ${ }^{2}$ ) for the polycyanurate are given in Table 2. The calculated density for bis-4-(4cyanatophenoxy)phenyl sulphone is $1.20 \mathrm{~g} \mathrm{~cm}^{-3}$, compared with the empirical density of the cured polymer of $1.34 \mathrm{~g} \mathrm{~cm}^{-3}$. The empirical value was measured at $298 \mathrm{~K}$, whereas the simulated value is given at zero Kelvin. This difference is related to temperature as the simulated value lies in the range of $1.31-1.34 \mathrm{~g} \mathrm{~cm}^{-3}$ during molecular dynamics at $300 \mathrm{~K}$.

Molecular dynamics data. The empirical determination of $T_{g}$ from changes in specific volume is accepted as a useful method in the analysis of thermomechanical properties in polymers ${ }^{22}$, although a gradual change in physical state is observed yielding a marked change in gradient. MD simulations were carried out on poly[bis4-(4-cyanatophenoxy)phenyl sulphone] in order to calculate the $T_{g}$ of the polycyanurate. The results from the initial molecular dynamics run (comprising six experiments at temperatures ranging from $700-200 \mathrm{~K}$ ) were promising and each run took approximately 200 hours of CPU time, significantly less than the 1000 hours in total previously required ${ }^{15}$ (on a smaller machine with a simpler model) using POLYGRAF. The data obtained from these MD experiments are shown in Figure 2 and the standard deviation in the data at each point are shown in Table 3. The initial analysis suggested that the $\mathrm{T}_{\mathrm{g}}$ (as evidenced by the marked change in gradient in the 
cell volume-temperature plot) lay in the region between 450 and $600 \mathrm{~K}$ (a simple extrapolation between these data yielded an intercept above $500 \mathrm{~K}$ ). However, consideration of these data and the trajectory files of the simulations performed suggested that equilibration had certainly not been achieved at the higher temperatures $(600 \mathrm{~K}$ and $700 \mathrm{~K})$ although there had been a levelling off of volume change at the lower temperatures.

\section{Insert Figure 2}

Initial MD simulation of "defect-free" poly(bis-4-(4-cyanatophenoxy)phenyl sulphone showing average cell volume versus simulation temperature (the broken lines are only indicative of the intersection and hence the $\mathbf{T}_{\mathrm{g}}$ )

\section{Table 3}

Standard deviations at each temperature for the MD simulations performed on the "defect-free" model for the polycyanurate of bis-4-(4-cyanatophenoxy)phenyl sulphone

Consequently, a longer simulation (lasting 1250 ps) was carried out solely on the $600 \mathrm{~K}$ structure using the final structure from the $700 \mathrm{~K}$ simulation as the starting point for the new simulation to reproduce the original experiment as accurately as possible. In order to clarify the point at which the discontinuity in the cell volume data occurred, three additional experiments were performed at $560 \mathrm{~K}, 520 \mathrm{~K}$ and 510 $\mathrm{K}$ (performed in descending temperature order) using the original $600 \mathrm{~K} \mathrm{MD}$ simulation as the starting point for these new simulations. Examination of the trajectory files demonstrates the greater degree of equilibration achieved (Figure 3). 
The $600 \mathrm{~K}(1250 \mathrm{ps})$ equilibration experiment took approximately one week to perform and the variation in the data remained fairly constant after 200 ps. This suggests that the structure will never achieve full equilibration nor explore a smaller range of energetic states as, at this temperature, there is a much larger number of conformations (of very similar volume and density and hence equal probability) that the polycyanurate can adopt.

\section{Insert Figure 3}

Trajectory files for the MD simulations performed at $510 \mathrm{~K}(150 \mathrm{ps}), 500 \mathrm{~K}$ (250 ps) and $600 \mathrm{~K}$ (1250 ps) for “defect-free”" poly[bis-4-(4-cyanatophenoxy)phenyl sulphone] showing average cell volume versus simulation time

Figure 4 shows the full data set including the original set of simulations and the subsequent "interpolation" experiments. The discontinuity appears to lie between $510 \mathrm{~K}$ and $520 \mathrm{~K}$ indicating the apparent glass transition temperature $\left(\mathrm{T}_{\mathrm{g}}\right)$ of the

polymer. An independent study, undertaken in a separate laboratory ${ }^{16}$, to determine the empirical $\mathrm{T}_{\mathrm{g}}$ for the same cured polycyanurate yielded values of $519 \mathrm{~K}$ (using DMA) and 508-528 K (using TMA) in close agreement with the simulation.

\section{Insert Figure 4}

Final MD simulations of "defect-free" poly[bis-4-(4-cyanatophenoxy)phenyl sulphone] showing average cell volume versus simulation temperature

Figure 5 shows the effect of the bulk polymer undergoing the apparent glass transition. In Figure 5a, the 27-unit cell 3-d model of poly[bis-4-(4- 
cyanatophenoxy)phenyl sulphone] is shown as constructed and minimised (prior to MD simulation); Figure $5 \mathrm{~b}$ represents the same model following the MD simulation at $510 \mathrm{~K}$ (after the apparent transition has occurred). The structure demonstrates the increased disorder in the model that is apparent following the MD experiment.

\section{Insert Figure 5}

27-unit cell 3-d models of "defect-free" poly[bis-4-(4-cyanatophenoxy)phenyl sulphone] (a) initial conformation and (b) following the MD simulation at $510 \mathrm{~K}$ (N.B., oxygen atoms are shown in red, nitrogen atoms in blue, sulphur atoms in yellow, carbon atoms in black and hydrogen atoms in white)

Effect of Structural Defects on the predicted $\mathbf{T}_{\mathbf{g}}$. The initial simulations were performed using "perfect" network structures in which every cyanate group was assumed to undergo reaction and also to contribute to the formation of a threedimensional network. However, in reality this is rarely achieved as most polycyanurates develop "structural defects" during the cure process. Bauer et al. ${ }^{23}$ have reported the results of a study of the curing behaviour of a commercial dicyanate, bis(3,5-dimethyl-4-cyanatophenyl)methane (otherwise known as AroCy M). They concluded that the occurrence of structural defects (of the form shown in Scheme 2) is particularly a problem when cyclotrimerisation catalysts are used during the cure process, although the generation of these structures was not predictable, nor reproducible. As this may occur during routine processing, it is important that any reliable simulation should be able to accommodate the inclusion of defects in the network stucture. In passing, it should be noted that FT-IR analysis ${ }^{16}$ of the cured polycyanurate (from which the empirical data were derived) showed no detectable 
quantities of the structural defect postulated by Bauer et al. This finding was evidenced by the lack of bands characteristic of the nitrile group - thought to arise from rearrangement of the cyanate group. This indicates that while the polycyanurate is unlikely to be perfect, it is unlikely to contain significant quantities of this structural defect, making the modelled structure a reasonable representation of the real material.

\section{Insert Scheme 2}

Reaction pathway postulated ${ }^{23}$ to form the structural irregularity (shown for bis(3,5-dimethyl-4-cyanatophenyl)methane, AroCy M). This structure would go on to polycyclotrimerize through the cyanate groups in the normal manner

Defects were added randomly to five of the 108 cyanurate rings in the original 27 -unit cell model. This would yield a fully converted polycyanurate network containing irregularities in around 5\% of the triazine rings in the structure - a similar figure was determined spectroscopically for AroCy $\mathrm{M}^{23}$. The modelling of the defects was not a trivial task since the 27 -unit cell is extremely complicated when viewed on screen. Consequently, limited success was achieved in placing the defects randomly through the entire structure and three out of the five defects were placed on the same (most easily accessed "front") plane. As the actual positioning of the defects (already random and variable) in the polycyanurate is not known, this "clustering" may not be unrepresentative.

\section{Insert Figure 6}

MD simulations of poly[bis-4-(4-cyanatophenoxy)phenyl sulphone] (containing ca. $5 \%$ structural defects) showing average cell volume versus simulation temperature 
Unfortunately, it has not been possible to measure the $\mathrm{T}_{\mathrm{g}}$ for a sample of poly[bis-4-(4-cyanatophenoxy)phenyl sulphone] containing the same number of defects, since their introduction is not controllable. However, the trend is a significant drop (of around $70 \mathrm{~K}$ ) in the value of $\mathrm{T}_{\mathrm{g}}$ of a "perfect" polycyanurate of bis-4-(4cyanatophenoxy)phenyl sulphone from ca. $520 \mathrm{~K}$ to $c a .450 \mathrm{~K}$ (Figure 6), along with an accompanying increase in the net cell volume. Both changes are consistent with an increase in the free volume of the system resulting from the introduction of structural defects and, hence, a reduction in the cross-link density. In their empirical study, Bauer et al. ${ }^{23}$ found that the polycyanurate of AroCy M underwent a reduction in the value of $\mathrm{T}_{\mathrm{g}}$ from $c$ a. $558 \mathrm{~K}$ for a "regular" sample representing a conversion of 96.4 $\%$ (and negligible irregularity) to $518 \mathrm{~K}$ for a sample representing a conversion of $93.8 \%$, containing highly irregular structures.

\section{Conclusions}

We do not adjust our $T_{g}$ values to the experimental conditions, we just compare the simulated $\mathrm{T}_{\mathrm{g}}$ values to those determined from experiment. Hence both determinations are independent and unbiased by each other. As the $T_{g}$ is not a first order thermodynamic transition, its experimentally determined value depends on how it is measured so there is always a range when measured experimentally. We seek to correlate the increase in volume of our system with temperature to the onset of main chain motion in the real system. In our latest paper on the simulation of benzoxazine systems [24] we have added a range for the experimental $T_{g}$ determinations to the specific volume versus temperature graph and this makes the agreement even better. We have also simulated and published on epoxy resins over the years using this technique albeit in a cruder implementation.

Other papers also published in Polymer have used similar techniques to ours to 
determine the $\mathrm{T}_{\mathrm{g}}$ from molecular simulation, e.g. Pozuelo and Baselga [25], where they studied poly(3-aminopropyl methyl siloxane) and found a $\mathrm{T}_{\mathrm{g}}$ of $213 \mathrm{~K}$ close to the experimental value. Also Wolfgang Paul [26] has discussed the subject of glass transition simulation in polymer melts using 1,4-polybutadiene as the example. These widely differing structures simulated under similar conditions point to the generality of the simulation technique and the confidence we can have in the results of such simulation.

The results of this study show that it is possible to reproduce the empirical density of this polymer with some accuracy using a large, but regular molecular model. It is also possible to simulate a transition, which can be compared with remarkable accuracy to the empirical $\mathrm{T}_{\mathrm{g}}$ Furthermore, it is possible to incorporate the latest evidence on the structural defects in these polymers and simulate the effect that incorporation of a small percentage of these has on the expected physical and mechanical properties of the polymer. The results from these 'defect' simulations are consistent with the drop in $T_{g}$ found in other polycyanurate systems.

Acknowledgement. We thank Hitachi Chemical Co. Ltd. (Tsukuba-shi, Japan) for funding part of this work in the form of a studentship (PK) and the EPSRC for a grant of computer time on Proton (Rutherford Appleton Laboratory, Cambridge). 
Table 1. Summary of data derived from Cerius ${ }^{2}$

Experiments for bis-4-(4-cyanatophenoxy)phenyl sulphone)

(for a given structural conformation)

\begin{tabular}{ll}
\hline Cell parameters & \\
\hline Density $\left(\mathrm{g} / \mathrm{cm}^{3}\right)$ & 1.20 \\
Volume $\left(\AA^{3}\right)$ & 4031 \\
Dimensions $(\AA)$ & 13.86 \\
$a$ & 22.36 \\
$b$ & 15.75 \\
$c$ & \\
Angles $\left({ }^{\circ}\right)$ & 120.34 \\
$\alpha$ & 81.65 \\
$\beta$ & 84.21 \\
$\gamma$ & \\
Mechanical properties & \\
Bulk modulus (GPa) & 4.37 \\
Young's modulus $(\mathrm{GPa})$ & 3.38 \\
& \\
\hline
\end{tabular}


Table 2. Bond distances and angles of the sym triazine ring for the polycyanurate of bis-4-(4-cyanatophenoxy)phenyl sulphone obtained using the RDA-

DR2.21_Inv forcefield (for the given conformation)

\begin{tabular}{|c|c|c|c|}
\hline & \multirow{2}{*}{$\begin{array}{c}\text { Bond distances }(\AA) \\
\text { C-N }\end{array}$} & \multicolumn{2}{|c|}{ Bond angles $\left({ }^{\circ}\right)$} \\
\hline & & C-N-C & N-C-N \\
\hline $\operatorname{Mean}^{a}$ & 1.336 & 112.25 & 127.72 \\
\hline Cyclotrimer $^{b}$ & 1.341 & 110.34 & 124.10 \\
\hline
\end{tabular}

${ }^{a}$ Average crystal data [from reference 17], ${ }^{b}$ Data represent cyclotrimer of bis4-(4-cyanatophenoxy)phenyl sulphone. 
Table 3. Standard deviations at each temperature for the MD simulations performed on the "defect-free" model for the polycyanurate of bis-4-(4cyanatophenoxy)phenyl sulphone

\begin{tabular}{lcccccc}
\hline Temperature (K) & 200 & 300 & 400 & 500 & 600 & 700 \\
\hline Standard deviation & 9.57 & 13.44 & 21.36 & 18.69 & 29.73 & 38.09 \\
\hline
\end{tabular}


Table 4 Comparison of actual and simulated physico-mechanical parameters for poly[bis-4-(4-cyanatophenoxy)phenyl sulphone].

Physico-mechanical Simulated value Experimental value
parameters

Density $\left(\mathrm{g} \mathrm{cm}^{-3}\right)$

1.20 (at zero $\mathrm{K}$ )

$1.31-1.34(\text { at } 300 \mathrm{~K})^{\mathrm{a}} \quad 1.34($ at $298 \mathrm{~K})$

$\mathrm{T}_{\mathrm{g}}(\mathrm{K})$

$510-520$

$519^{\mathrm{b}}$

$508-528^{c}$

${ }^{\text {a }}$ Data derived from simulation experiment performed at $300 \mathrm{~K}$.

${ }^{\mathrm{b}}$ Data obtained from DMA in tensile mode at $1 \mathrm{~Hz}$ on cured neat resin samples between $123 \mathrm{~K}$ and $623 \mathrm{~K}$ at a heating rate of $5 \mathrm{~K} \mathrm{~min}^{-1}$ (originally published in reference 16).

${ }^{\mathrm{c}}$ Data obtained from TMA on cured neat resin samples at a scanning rate of $5 \mathrm{~K} \mathrm{~min}^{-1}$ (originally published in reference 16).

N/A not measured. 


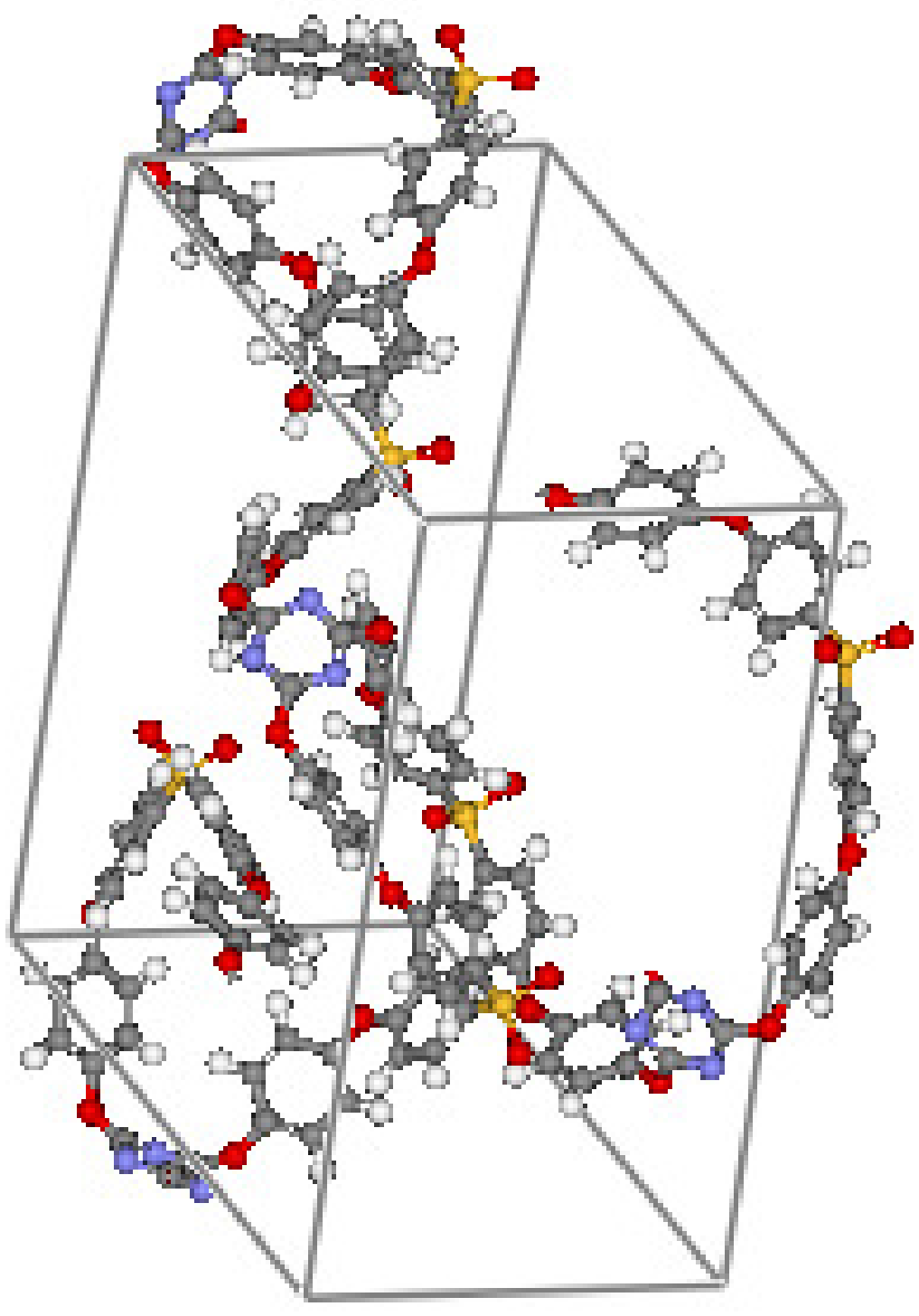

Figure 1. "unit cell" of bis-4-(4-cyanatophenoxy)phenyl sulphone (N.B., oxygen atoms are shown in red, nitrogen atoms in blue, sulphur atoms in yellow, carbon atoms in black and hydrogen atoms in white) 


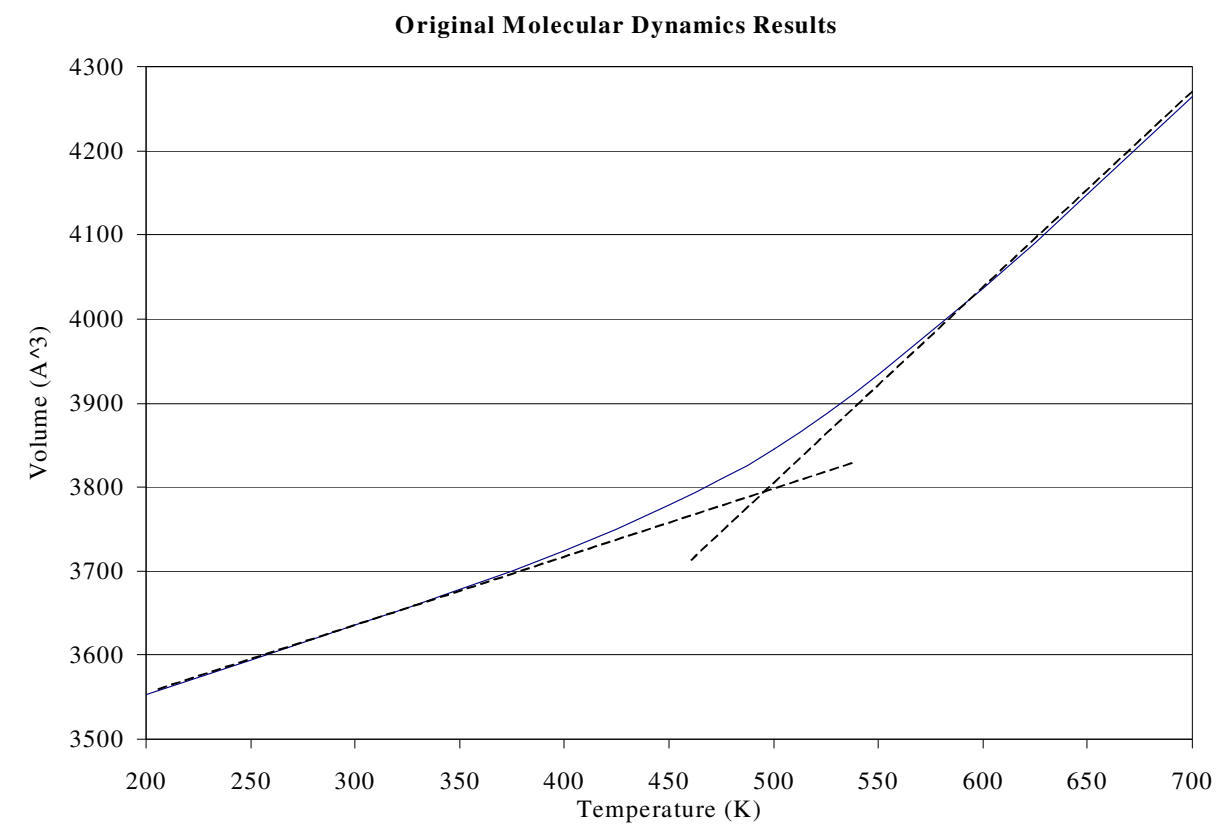

Figure 2. Initial MD simulation of "defect-free" poly[bis-4-(4cyanatophenoxy)phenyl sulphone] showing average cell volume versus simulation temperature (the broken lines are only indicative of the intersection and hence the $\mathrm{T}_{\mathrm{g}}$ ) 

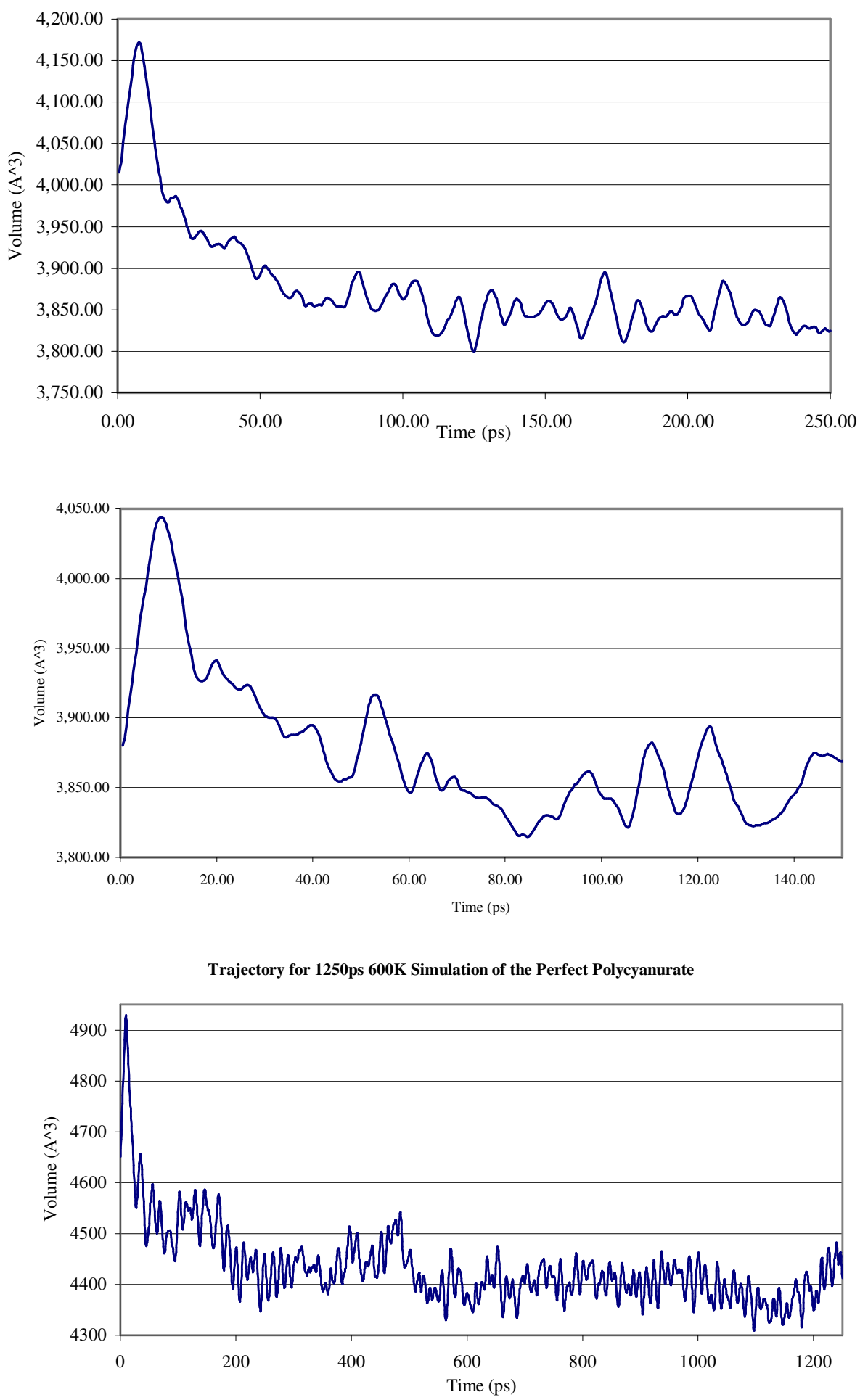

Figure 3. Trajectory files for the MD simulations performed at (from top) $510 \mathrm{~K}$ (150 ps), $500 \mathrm{~K}(250 \mathrm{ps})$ and $600 \mathrm{~K}(1250 \mathrm{ps})$ for "defect-free" poly[bis-4-(4cyanatophenoxy)phenyl sulphone] showing average cell volume versus simulation time 


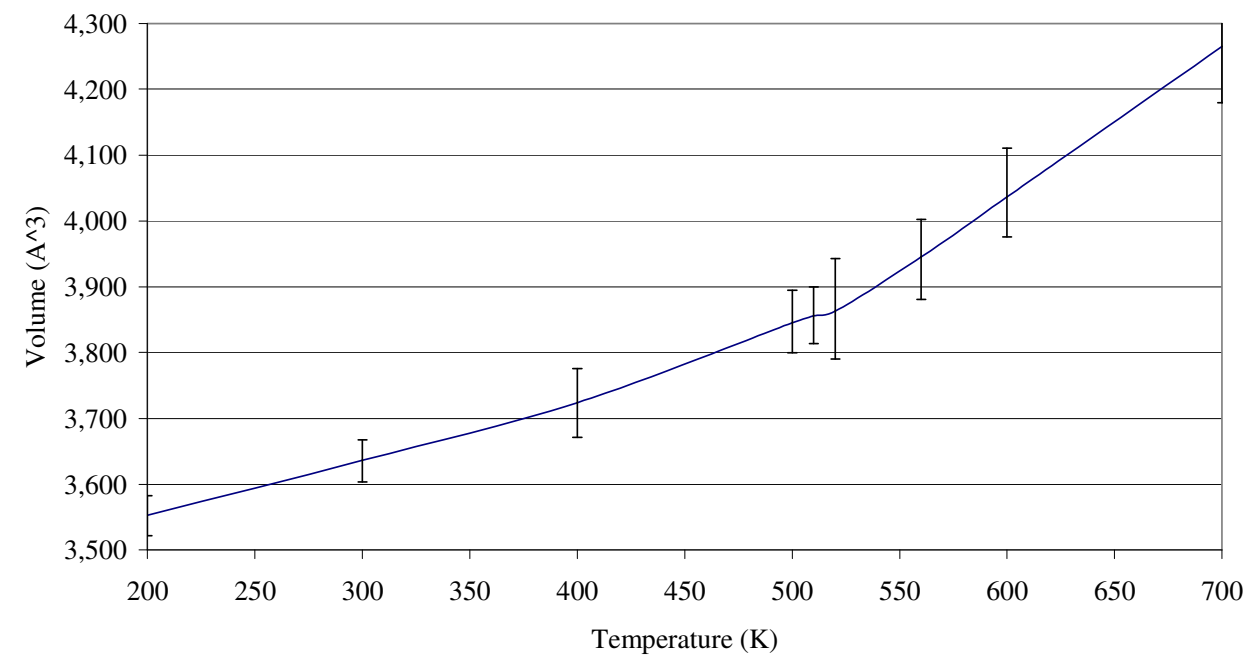

Figure 4. Final MD simulations of "defect-free" poly[bis-4-(4cyanatophenoxy)phenyl sulphone] showing average cell volume versus simulation temperature 
(a)

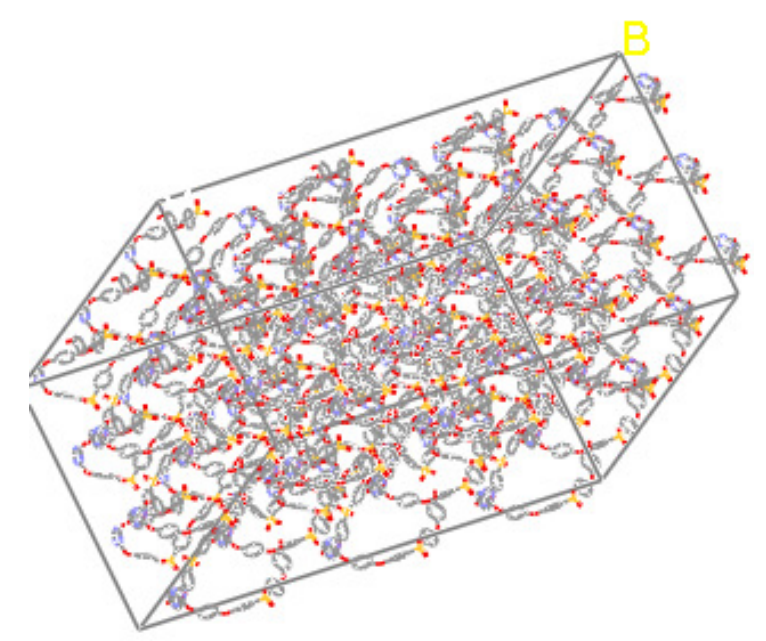

(b)

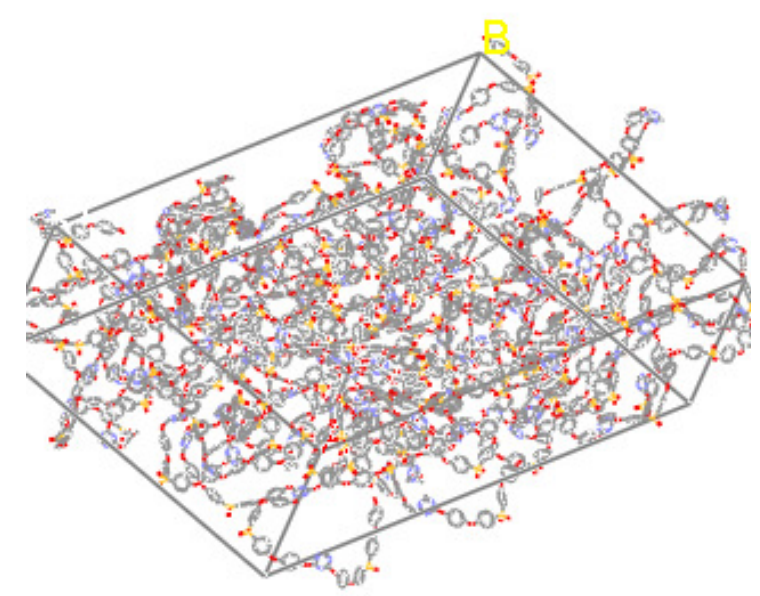

Figure 5. 27-unit cell 3-d models of "defect-free" poly[bis-4-(4cyanatophenoxy)phenyl sulphone] (a) initial conformation and (b) following the MD simulation at $510 \mathrm{~K}$ (N.B., oxygen atoms are shown in red, nitrogen atoms in blue, sulphur atoms in yellow, carbon atoms in black and hydrogen atoms in white) 


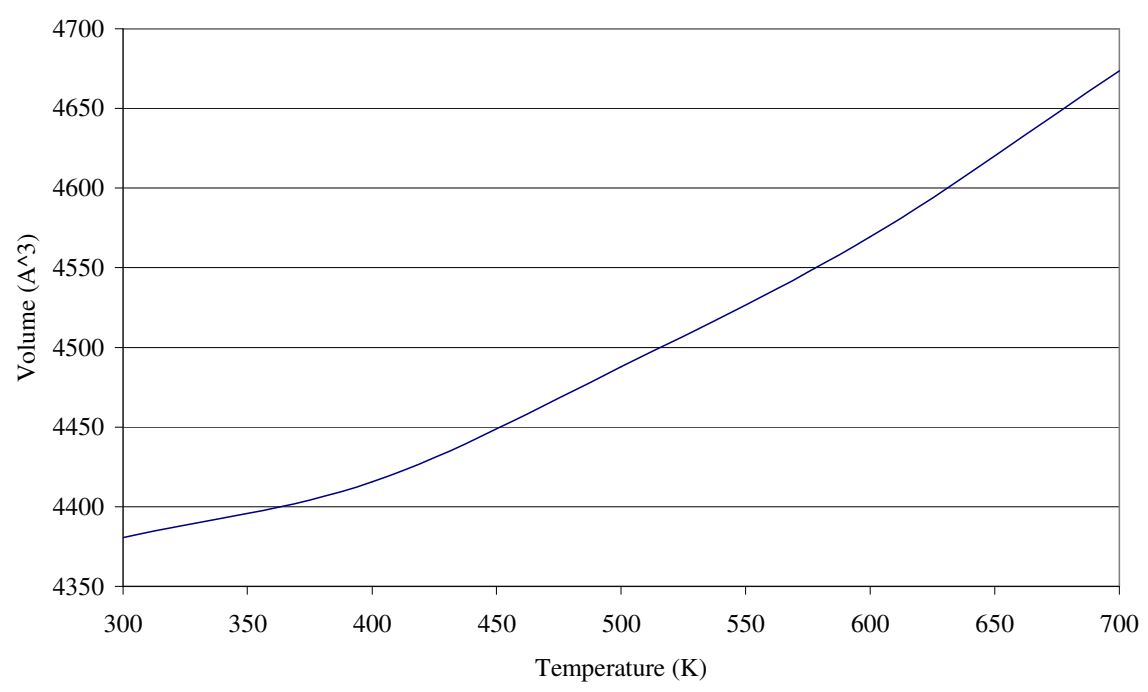

Figure 6. MD simulations of poly[bis-4-(4-cyanatophenoxy)phenyl sulphone] (containing $\mathrm{ca} .5 \%$ structural defects) showing average cell volume versus simulation temperature 


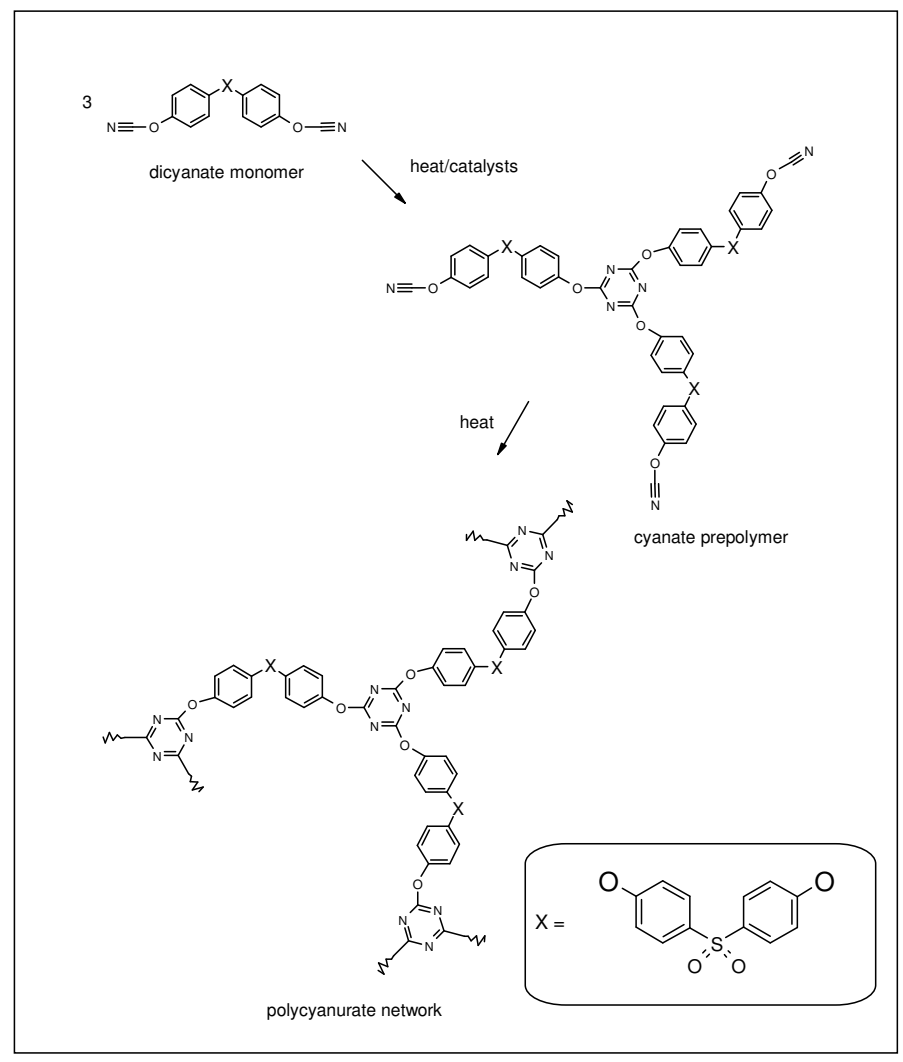

Scheme 1. Simplified cyclotrimerisation reaction to produce polycyanurate network (shown for bis-4-(4-cyanatophenoxy)phenyl sulphone). 


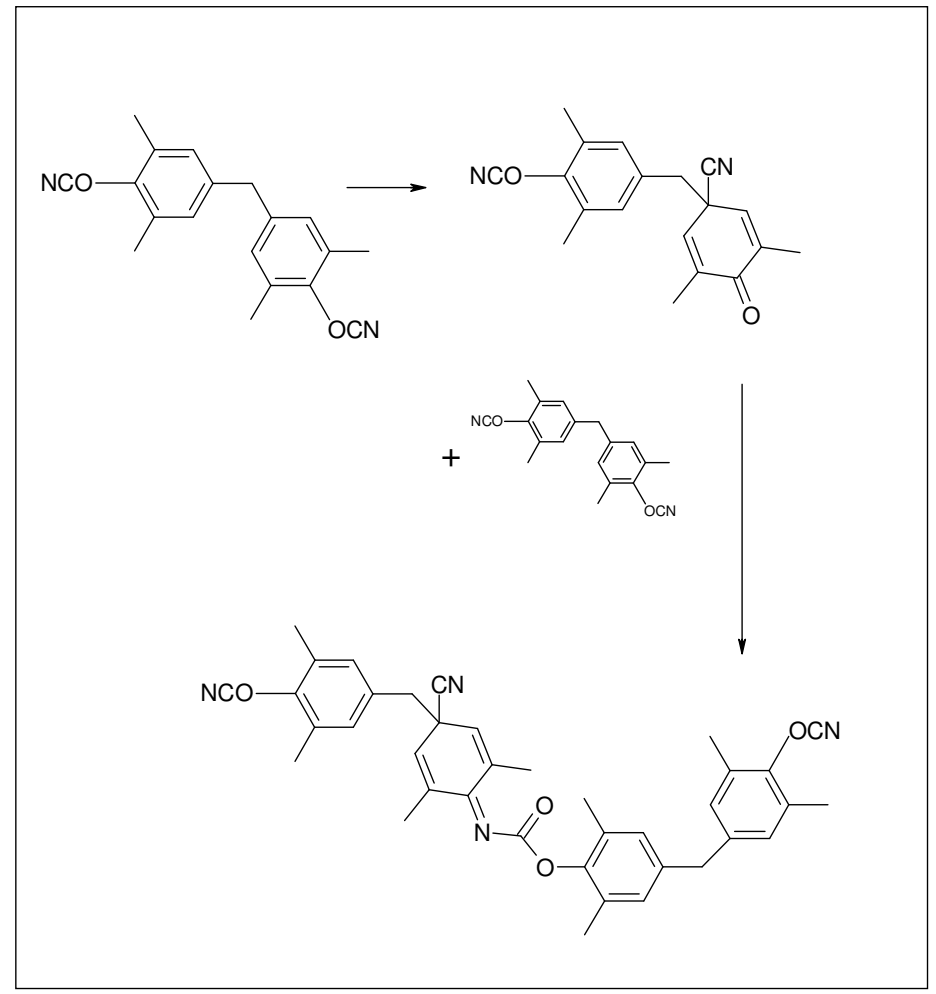

Scheme 2. Reaction pathway postulated ${ }^{23}$ to form the structural irregularity (shown for bis(3,5-dimethyl-4-cyanatophenyl)methane, AroCy M). This structure would go on to polycyclotrimerize through the cyanate groups in the normal manner 


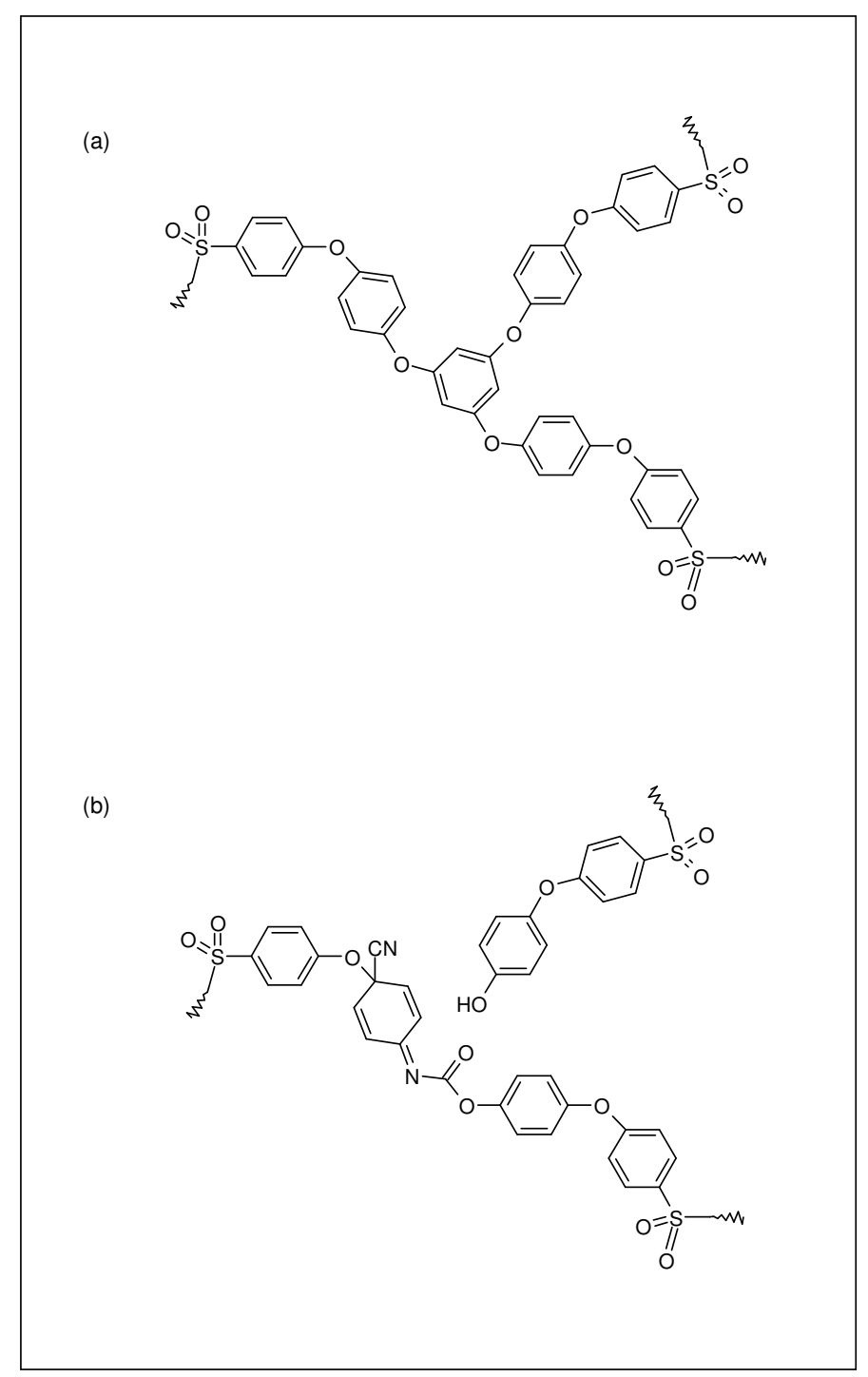

Scheme 3. (a) Portion of "defect-free" network used in simulation (b) introduction of defect showing residual hydroxyl group on adjacent chain 


\section{References}

(1) Hamerton, I. Introduction to Cyanate Ester Resins. In Chemistry and Technology of Cyanate Ester Resins, Hamerton, I., Ed.; Blackie Academic and Professional: Glasgow, 1994; pp. 1-6.

(2) Shimp, D. A. Technologically Driven Applications. In reference 4, pp. 319-323.

(3) Korshak, V. V. Pure Appl. Polym. Chem., 1974, 39, 65.

(4) Kasehagen, L. J.; Macosko, C. W. Polym. Internat., 1997, 44, 237.

(5) Richer, S.; Alamercery, S.; Delolme, F.; Dessalces, G.; Paisse, O.; Raffin, G.; Sanglar, C.; Waton, H.; Grenier-Loustalot, M. F. Polymers and Polym. Compos. (2002) in press.

(6) Fang, T.; Houlihan, F. M. Polym. Prepr., 1994, 35, 535.

(7) Shimp, D. Proc. ACS Div. Polym. Mater. Sci. Eng., 1994, 71, 813.

(8) Hamerton, I.; Emsley, A. M.; Howlin, B. J.; Klewpatinond, P.; Takeda, S. Studies on a dicyanate containing four phenylene rings and polycyanurate blends. 2. Application of mathematical models to the catalysed polymerization process, submitted to Polymer (2002).

(9) Warner, P. T.; Warner, J. C. Green Chemistry Theory and Practice, Oxford University Press: Oxford, 1998 p 30.

(10) Azapagic, A.; Emsley, A. M.; Hamerton, I. Polymers the Environment and Sustainable Development, Hamerton, I., Ed.; John Wiley: Chichester, 2003, pp. 174-178.

(11) Goodman, J. M Chemical Applications of Molecular Modelling, Royal Society of Chemistry: Cambridge, 1998, pp. 176-181.

(12) Boyd, R. H. Trends Polym. Sci., 1996, 4, 12.

(13) Hamerton, I.; Heald, C. R.; Howlin, B. J. Model. Simul. Mater. Sci. Eng., 1996, 4, 151.

(14) Barton, J. M.; Deazle, A. S.; Hamerton, I.; Howlin, B. J.; Jones, J. R. Polymer, 1997, $38,4305$.

(15) Hamerton, I.; Heald, C. R.; Howlin, B. J. J Mater. Chem., 1996, 6, 311.

(16) Hamerton, I.; Howlin, B. J.; Klewpatinond, P.; Takeda, S. Polymer, 2002, 43, 5737.

(17) Allington, R. D.; Attwood, D.; Hamerton, I.; Hay, J. N.; Howlin, B. J. Comput. Theor. Polym. Sci. (2001) 11, 467

(18) Gasteiger, J.; Marsili, M. Tetrahedron (1980) 36, 3219

(19) Hamerton, I.; Howlin, B. J.; Klewpatinond, P.; Takeda, S. Polymer (2002) 43, 4599

(20) Bauer, J.; Alla, C.; Bauer, M. Acta Polym., (1995) 46, 241

(21) Bauer, M.; Bauer, J. Abstr. Pap. Am. Chem. Soc. (1994) 208, 299

(22) Kovacs, A. J. J. Polym. Sci. (1958) 30, 131

(23) Bauer, M.; Uhlig, C.; Bauer, J.; Harris, S.; Dixon, D. Side reactions during polycyclotrimerisation of cyanates and their influence on network and structure properties, Chapter 23 in Wiley Polymer Networks Group Review Series, Volume 2, Stokke, B. T. and Elgsaeter, A. (Eds.), John Wiley and Sons, Ltd. (1999), pp. 271-283

(24) Hamerton I, Howlin BJ, Mitchell AL. Reactive and functional polymers. (2006) 66, 21.

(25) Pozuelo, J and Baselga J. Polymer (2002) 436049

(26) Paul, W. Polymer (2004) 453901 